\title{
THE INDIVIDUALIZATION OF ERP IN SMES FOR SUSTAINABLE DEVELOPMENT
}

\author{
Dr. Wurong Shih \\ Assistant Professor \\ School of Business and Management \\ Southern Taiwan University of Science and Technology, Taiwan \\ E-mail: wurong@stust.edu.tw \\ Dhttps://orcid.org/0000-0003-1186-2389 \\ Dr. Julián Nevárez Montes \\ Professor \\ School of Business and Management \\ Southern Taiwan University of Science and Technology, Taiwan \\ E-mail: da41g203@stust.edu.tw \\ (iD https://orcid.org/0000-0002-5465-1533
}

Received: October 03, $2021 \quad$ Accepted: December 01, $2021 \quad$ Online Published: February 03, 2022

DOI: $10.46281 /$ ijsmes.v5i1.1586

URL: https://doi.org/10.46281/ijsmes.v5i1.1586

\begin{abstract}
This paper aims to prove that software such as Enterprise Resource Planning (ERP) is not designed properly and is out of the awareness of most Small and Medium Enterprises (SMEs). The Expectation-Confirmation model took role as a way of understanding this behavior and the application of a questionnaire of validation in three specific areas: sales, inventory management and customer satisfaction to 47 hair salons in Bolivia, Chile, China, Colombia, Ecuador, Mexico, Peru, The U.S. and Taiwan. A concise finding is that in fact, managers, owners and employees in hair salons are not aware of the existence of ERP solutions and the possible application to their business so that their sustainable development is achieved; also, the main finding is that $87 \%$ are willing to learn and acquire it.
\end{abstract}

Keywords: ERP, SMEs, Standardization, Innovation, Individualization, Sustainability.

JEL Classification Codes: A19, B10, B25, C10, C53.

\section{INTRODUCTION}

The endless search for cost-reducing and innovation has been a constant in business. According to the OECD, the SMEs contribute to more than $90 \%$ of employment sources and generate significant domestic and export earnings (OECD, 2004). Many managers and business owners think that once their business is going well, they do not need to do anything else, but in fact, this is when innovation and real growth comes in. 
SMEs play a very powerful role in every developing country. The opening of countries' frontiers and globalization, has brought a difficult paradigm to SMEs and to trade. It is hard for companies to struggle with cheap imports and variance in the market prices and foreign competitors, so the best way of encouraging and promoting real changes in SMEs is to provide enough training and tools to be able to compete fairly in this globalized era and its challenges. (OECD, 2004)

SMEs can be measured by their capital size and by the number of employees. In most of the countries, companies can be considered SMEs if they have no more than 200-250 employees. While in some specific countries like Japan, the number of employees is 500 and in the United States, the number is up to 300 .

Therefore, this report is aimed to serve as a comparison with the current benefits SMEs are having once they have implemented the ERP solutions and the ones who have not. In the research conducted by Fui-Hoon, it is stated that it is very important to create a vision towards the goals and even the business plan impact that implementing an ERP project would cause.

In case you are thinking which comes first, the egg or the chicken; understanding the importance and benefits provided by current software solutions and innovations might give a substantial boost to SMEs. On the other hand, having a clear idea of the influence and effect this implementation will have is something that you will need to discuss deeply with your collaborators.

\section{What is ERP?}

At the beginning, many different industries were using systems which could provide Inventory Control. Then in 1970's, this concept changed to be called Material Requirement Planning. But it was until the 1980's when the concept took a new dimension as it included areas just like finance, engineering, and human resources. MRP allowed managers to plan the production and raw materials by working backward from the sales forecast, the prediction of future sales (Monk \& Wagner, 2012).

Enterprise Resource Planning is a large, integrated system handling business processes and data storage for a significant number of business units and business functions (Gattiker \& Goodhue, 2000). The inclusion of ERP systems in organizations brings a fusion among the corresponding departments within the enterprise. It allows each one of them to access important data and information about the company's processes. The ERP are software packages that enable companies to integrate their business processes and all the information relevant to their organization (Nah \& Delgado, 2006).

The strategy for developing SMEs shall be integrated in a complex national strategy including the areas of poverty reduction and economic growth within the developing countries. (OECD, 2004) ERP is merely a server to automate operations from the supply chain management, inventory control, manufacturing, scheduling and production, human resources, sales, customer relationship management and to any other process involved in management (Hitt, $\mathrm{Wu}, \&$ Zhou, 2002).

So then, if it is clear that having such software, an improvement of the elements of the company and a visible facilitation of resources and information is provided, why do so many companies think differently or why do they not want to see it? In the following chart, you can mostly see the general composition of an ERP system (See figure 1). 


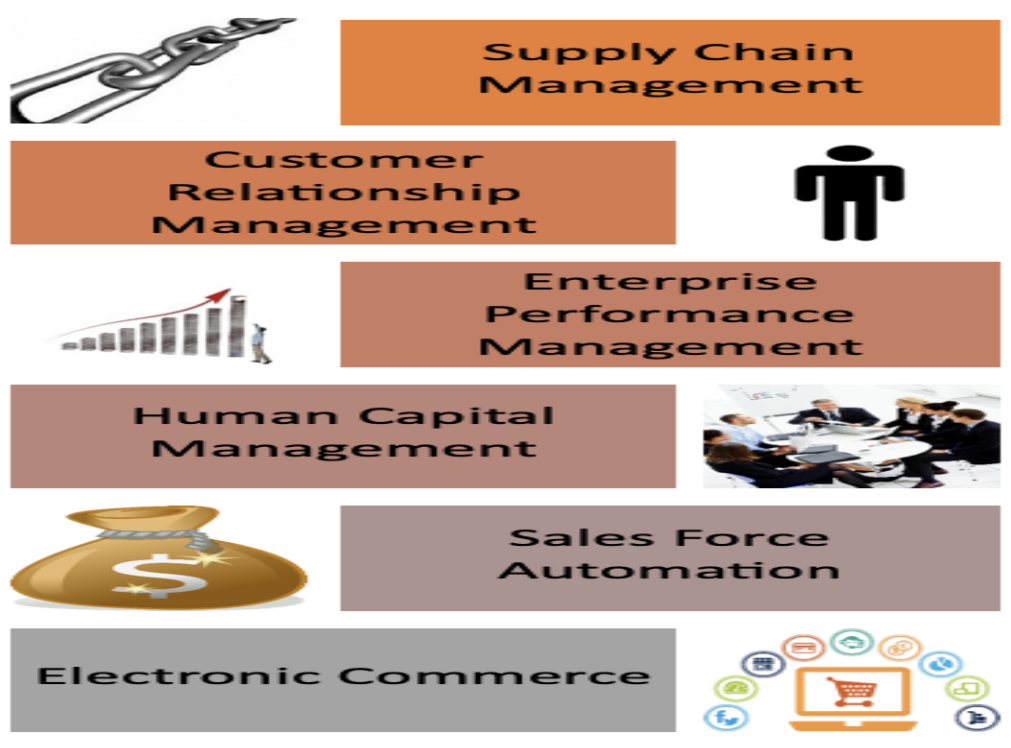

Figure 1. ERP integration (Monk \& Wagner, 2012).

The main purpose of implementing ERP in companies is to provide reliable information in order to improve business processes and to be able to lower costs; in other words, to create and to surge the operating efficiency.

\section{Definition and Characteristics of SMEs}

Small and Medium Enterprises have a wide variety of business models. From the small tea shop around the corner to the fastener manufacturer in an industrial park. These SMEs could have different scopes which could go from local, domestic, rural, and international. As mentioned before, the OECD defines the SMEs according to the number of employees existing on it. These could vary from country to country. The most common cipher is to be on a limit between 200250 employees. While in countries like Japan it could be 500 or in the United States it could be 300. (OECD, 2004)

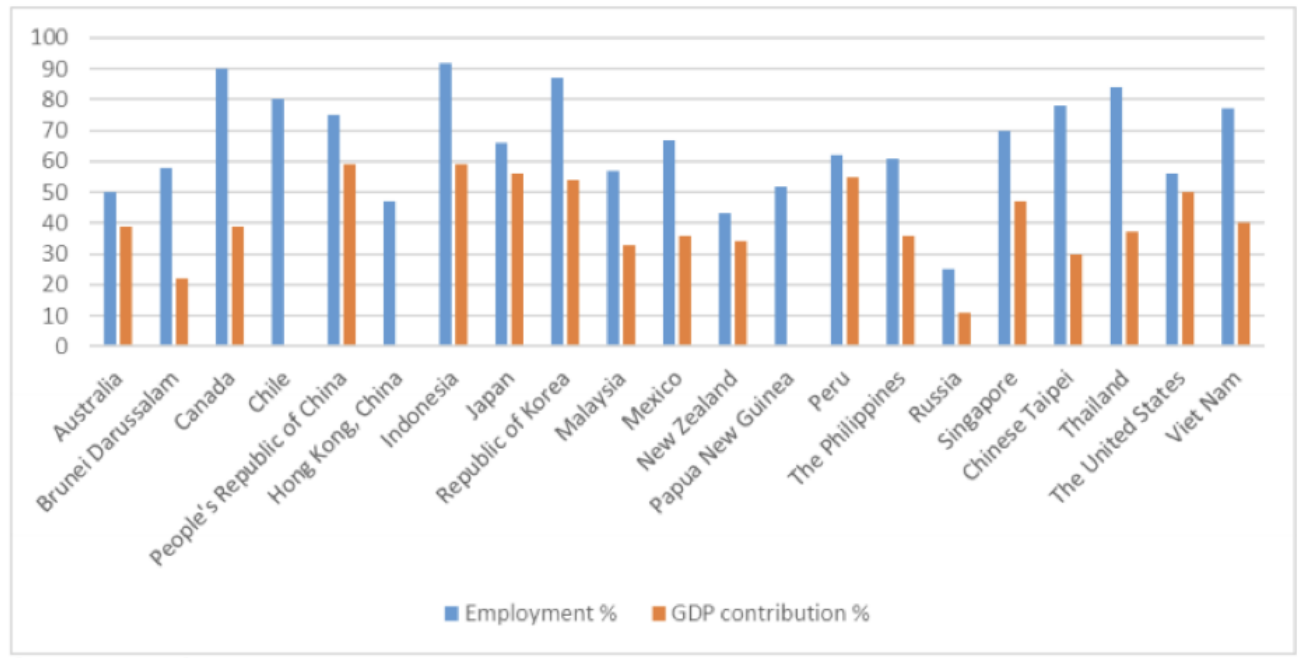

Table 1. Small and Medium Enterprises by employment and GDP as percentage (Small and Medium Enterprises Working Group, 2015). 
It is a fact that SMEs are deeply affected by micro and macroeconomic aspects, then, policies accepted and implemented in the globalization era have to be considered by managers, entrepreneurs and start-ups. The European Commission established four quantitative criteria in 1996 to define the SMEs:

- The Annual Turnover.

- The total of Assets.

- The Number of employees.

- The degree of independence of the enterprise.

Big firms might see SMEs as their own roots and a possible future competitor. For professionals and people in the business market, SMEs are a possible way of working and it could be their first job opportunity. Even, for some people with the required skills, the corresponding knowledge and the perfect attitude; SMEs could be their entrepreneurship project. Therefore, if SMEs are so important in every economy or country, their development and integration to globalization is compulsory.

In 2003, the EC made some alterations to increase the turnover amount of SMEs and the value of their annual balance. There is no doubt that SMEs are important in any country since they are the representation of the real growth and the difference in the developing countries and emergent economies. The OECD states that SMEs represent $60-70 \%$ of the jobs in the countries. The capacity for innovation and creation of new products is, in fact, a plausible characteristic of SMEs. To be able to appreciate the magnitude of the SMEs around the world, the World Bank and the International Finance Corporation, released a report conducted by Khrystyna Kushnir where they identify these SMEs (See Figure 2).

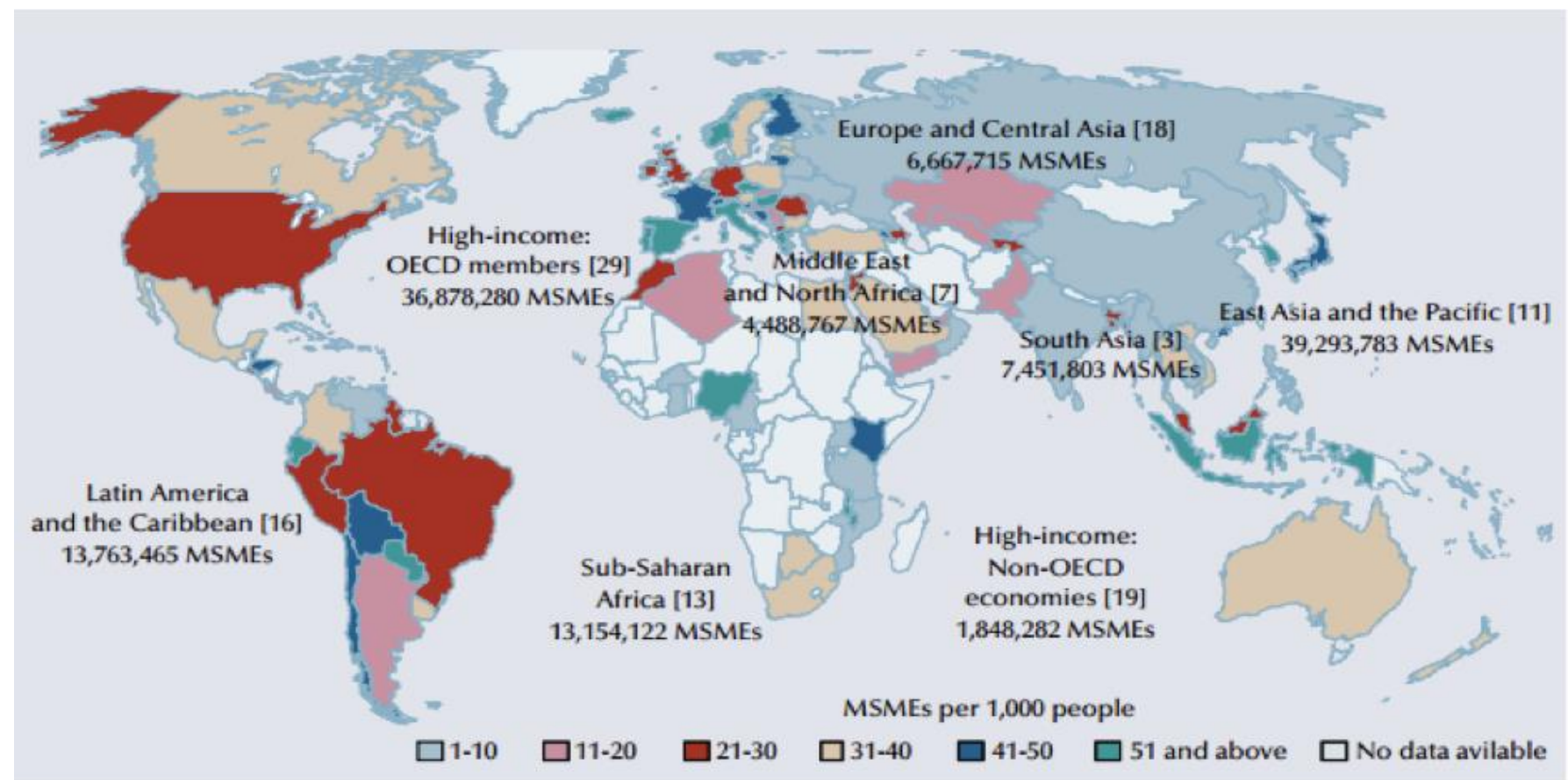

Figure 2. Micro-Small and Medium Enterprises Density around the World (Kushnir,

Mirmulstein, \& Ramalho, 2010).

In this intensive report, the Micro, Small and Medium Enterprises can be easily identified around the world. While in some countries like the United States, Brazil, Peru, Germany or 
England, the density of MSMEs goes around 21-30 per 1,000 people. In other countries like Mexico, South Africa, Australia and Poland, just to mention some of them, the density of MSMEs goes from 31-40 per 1,000 people.

Therefore, the impact of the SMEs in the local, domestic and global economy is highly considered to be the main source of the Gross Domestic Product.

\section{PURPOSE OF THE STUDY}

Globalization has produced a higher demand for professionalization in the business processes and of course inside of every economy. Then, encouraging enterprises and advising them on how to deal with the global changes and the current economic situation will let them overcome the future challenges.

The idea of having useful information and data available for every department and every corner of the company is an essential aid in making decisions, planning and organizing.

Then, this paper aims at analyzing the behavior in SMEs; specifically in hair salons. The adaptation they have in new technologies like ERP and the awareness of the benefits provided by this technology.

Moreover, this paper aims at providing an individualized data base of needs to L'Oreal ${ }^{\circledR}$ in order to perform the required adjustments to create a unique software solution for hair salons.

\section{LITERATURE REVIEW}

The main idea might come to analyze how ERP was created or how ERP could be substantially helpful for SMEs. Well, as customers' needs and expectations have changed; said this in order to explain the enormous way in which services are required with haste and efficiency, companies must provide these services with the mentioned characteristics and also at a very low price (or less than the competency).

\section{Why Information Systems Matter?}

Every department or area in a company creates, analyses and provides data. This is sent and received from different areas. The process is not only to send and receive but to act according to the information provided. This information could result in efficiency or inefficiency. If companies share data within their areas, they can become more competitive.

An example could be: a shipping company has received a new customer and submitted an order to send some documents to a different country. The customer was attended by the front desk. Front desk has to print out the customer's address and the mailing address. Front desk hands out the order to the shipping office. It has to tag the package with the corresponding mailing information. Two things could happen here: it is time-consuming, the data has been written two different times and there might be an error in the submission.

Monk and Wagner (2012) from the University of Delaware, relates in her book, Concepts in Enterprise Resource Planning that "Spreadsheet software, a fundamental business tool today, became popular in the 1980s. With spreadsheets, managers could perform complex business analyses without having to rely on a computer programmer to develop custom programs". Many SMEs currently use this technology but, most of them do not even know how to use a computer (Speaking about micro enterprises). Then, their processes become harder and unidentifiable for others. If some day for some reason the manager or the owner leaves the office or shop, there is a risk that employees might not know how to continue. In order to be able to reduce poverty in countries, there must be a very special aim in creating employment, and promoting economic 
growth.

For Bartlett (2004), a set of technological, economic and social development are driving the motivation towards internationalization, making it indispensable and vital for companies to be able to evolve and be ready for the business.

\section{The Readiness for ERP}

Implementing an ERP package is a complex and costly undertaking, so it's essential to choose the appropriate vendor, adequate scalability features and suitability (Dixit, 2011). With ERP systems, firms are able to manage all their resources (i.e., physical or intangible assets, finances, human resources, production, etc.) more effectively (Nah \& Delgado, 2006).

Over a period of 40 years, the Information Systems (IS) discipline has become an essential component in the employment of information technology personnel in business and government organizations (Hawking, 2004).

Globalization has resulted in increased competition amongst firms, as such managers of today are increasingly seeking different ways and approaches to achieve, improve, and sustain organizational performance and competitive advantage (Fening, 2012). Sustainability reporting involves reporting this impact to a broader base of business stakeholders including customers, suppliers, local communities, employees, and society at large (Webb et al., 2012). Most of the foreign countries are realizing the fact that SMEs contribute a major portion of the country's GDP and economic activity and they hold an important place and get the similar effects when a business policy is laid by the government for larger businesses (Jasra et al., 2011).

Globalization has led to the spread of business and cultural activities across the globe. The term is rather confusing. Globalization is used by some to refer to the efforts of the International Monetary Fund (IMF), the World Bank and others to create a global free market for goods and services (Ocloo et al., 2014).

\section{METHOD}

This study took a sample from different countries in which they have hair salons. The main idea is to collect their opinions and behavior according to three factors: Sales, customer's satisfaction and inventory management.

The questionnaire was translated to Chinese in order to analyze the Asian region as well. The questionnaires both in English, Chinese and Spanish were sent to different Facebook groups where the community is whether a hair salon manager, owner, employee or responsible of the branch.

The structure of the questionnaire denotes a factual behavior of the managers in which the awareness, usage and application of ERP solutions will be pinpointed. The model or theory of Expectation-confirmation (ECT) is commonly mentioned in research and writings to learn about consumer satisfaction, services evaluation and marketing.

Specific questions have been targeted to boost an expectation in the hair salon managers, employees, owners and participants in order to reevaluate this feeling once they are aware of the possibility of including the software in their businesses.

A possible approach would be defined as seen on figure 3. The Causal Relationship Diagram of ERP in SMEs. 

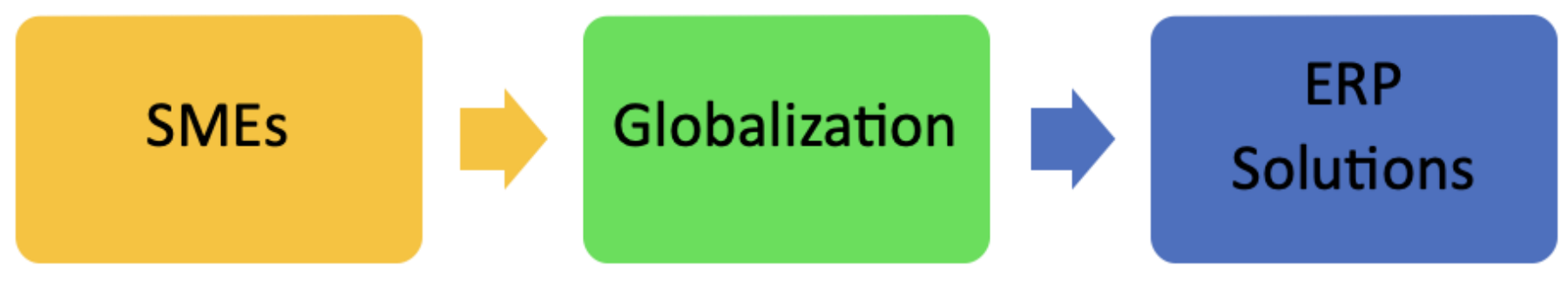

Figure 3. Causal Relationship Diagram of ERP in SMEs.

Consequently, the power and impact of SMEs in the local economy, the opening of barriers, hindrances and the unstoppable globalization has brought as a result the search for more effectiveness, control and profitability.

In figure number 4 , we can observe the ECT as a diagram and the relationship between each one of the components, its main constructs and key components. According to Oliver (1980), the process in which customers are involved in their capability of deciding whether to buy the product or not. The model can be explained in five different stages:

STAGE 1. Expectation: it is where any consumer might have an idea of what they want. A possible solution for one or many of their needs.

STAGE 2. Purchase: The customer accepts a product to fulfill the expectation and is taken to an initial consumption.

STAGE 3. Confirmation: the customer evaluates the performance in relationship to what they had expected the product would be able to do.

STAGE 4. Satisfaction: according to the differences of the expectation and the confirmation throughout the evaluation, the customer forms an idea based on the level of expectation.

STAGE 5. Repurchase Intention: If the software was not according to the expectations set by the customer, it will discontinue using it. On the other hand, if the software provides enough capabilities to satisfy the expectations of the customer, it will continue.

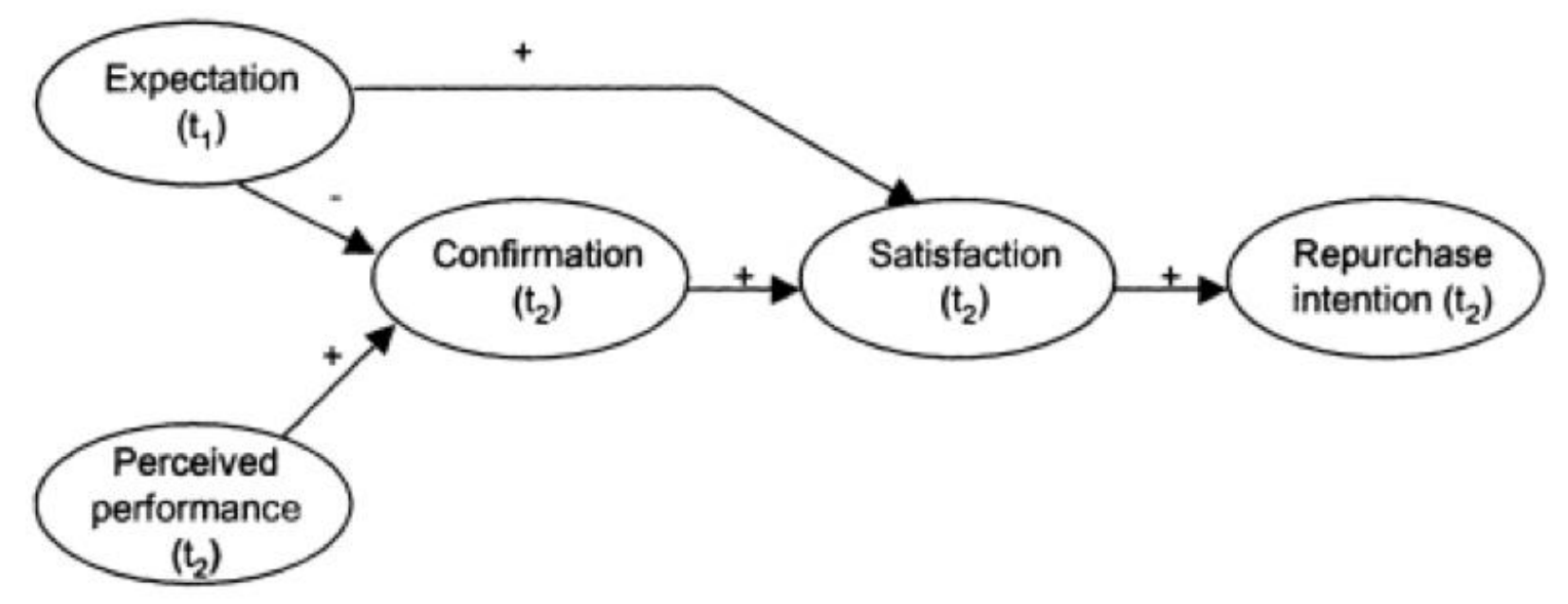

Note: $t_{1}=$ pre-consumption variable; $t_{2}=$ post-consumption variable

Figure 4. Expectation-Confirmation Model. 


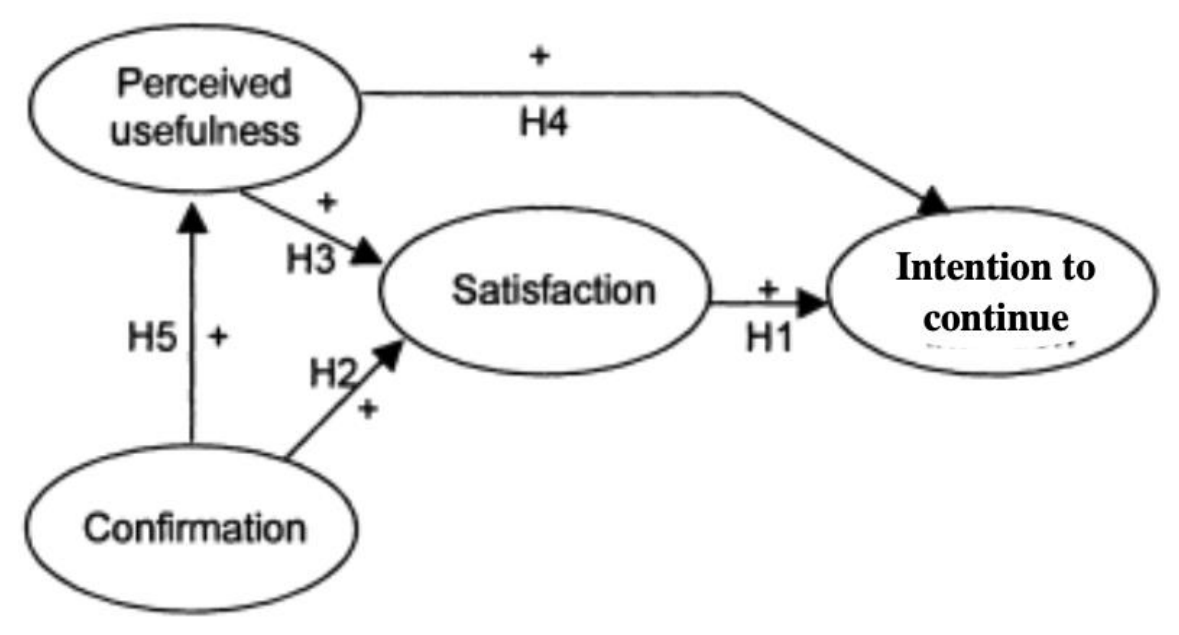

Figure 5. The model after the acceptance of the software.

\section{DATA ANALYSIS}

In order to collect the data, the questionnaire was translated to three different languages: Spanish, English and Chinese. The main idea of translating it to these languages is due to they are the top ten languages in the world. (Internet World Stats, 2014)

A research in Facebook groups was done and the inclusion in 17 of them was possible. Each group has an average number of participants of 15886.1. The table 1 shows the information from each one of them. To avoid the usage of names, each group has been classified as follows:

Table 2. Relationship of Facebook groups per number and language.

\begin{tabular}{|c|c|c|}
\hline Name & Number of users & Main Language \\
\hline Group 1 & 219 & Chinese \\
\hline Group 2 & 1590 & Chinese \\
\hline Group 3 & 132 & Chinese \\
\hline Group 4 & 10658 & Spanish \\
\hline Group 5 & 29179 & Chinese \\
\hline Group 6 & 237 & Chinese \\
\hline Group 7 & 432 & English \\
\hline Group 8 & 895 & English \\
\hline Group 9 & 91036 & English \\
\hline Group 10 & 16330 & English \\
\hline Group 11 & 3786 & English \\
\hline Group 12 & 2017 & Spanish \\
\hline Group 13 & 1863 & English \\
\hline
\end{tabular}




\begin{tabular}{|l|c|l|}
\hline Group 14 & 108360 & English \\
\hline Group 15 & 1876 & Spanish \\
\hline Group 16 & 1345 & Spanish \\
\hline Group 17 & 109 & Spanish \\
\hline
\end{tabular}

The questionnaire was sent directly to each group in which the common participation is from hair salon managers, independent hair stylists, hair salon owners and I could say that in prevention of any misunderstanding, other users might be included. A number of 47 responses were able to be collected at the time. We can see the main languages from where we obtained more responses in the figure 6.

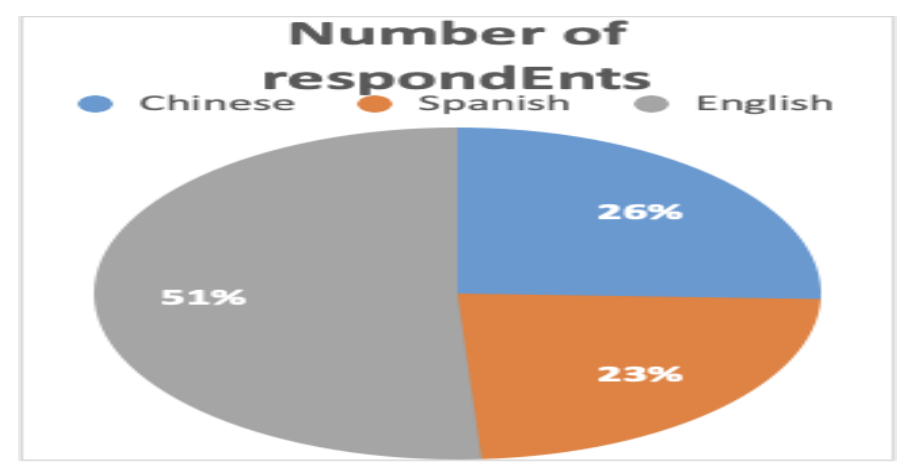

Figure 6. Distribution of respondents per language spoken.

Something important to consider in this collection of data was the country in which the hair salon is located, so as part of the questionnaire, the respondents were asked to provide the location of their hair salon. The Figure 7 shows the distribution of the respondents according to this reference.

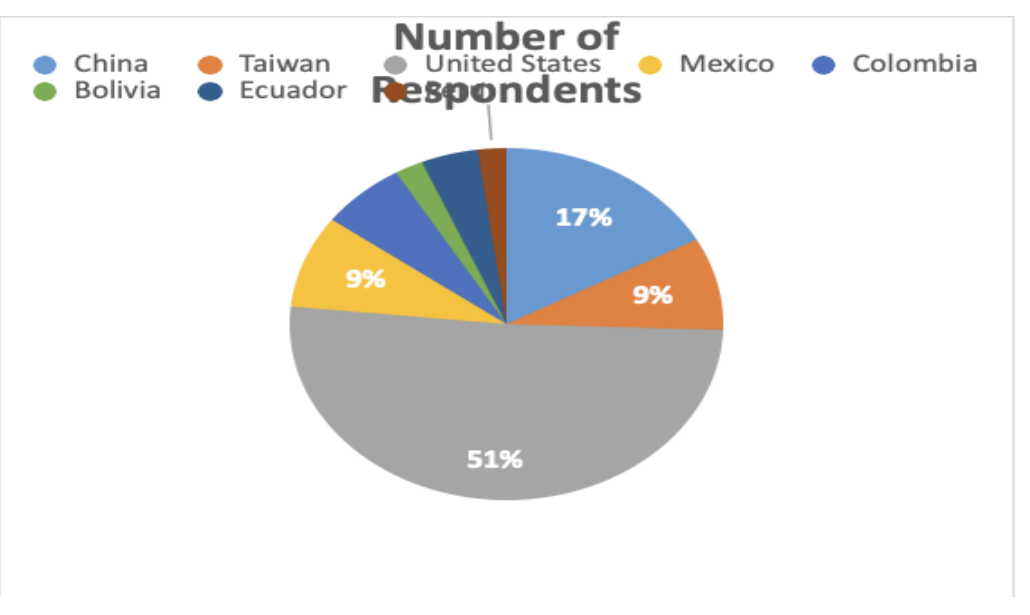

Figure 7. Distribution of respondents per country of origin.

As we can observe, most of the participants come from the United States, then from China and on the third place is Mexico and Taiwan. Since this project is focused on SMEs, the consideration of the number of employees working in the hair salon was important and a graphic 
to identify the distribution of employees was done, having as a higher number hair salons with 32 employees and the lowest with only 1.25 out of the 47 respondents have from 1 to 10 employees. 16 out of the 47 respondents have from 11 to 20 employees. 4 out of the 47 respondents have from 21 to 30 employees. 2 out of the 47 respondents have from 31 to 40 employees. 0 out of the 47 respondents have more than 41 employees.

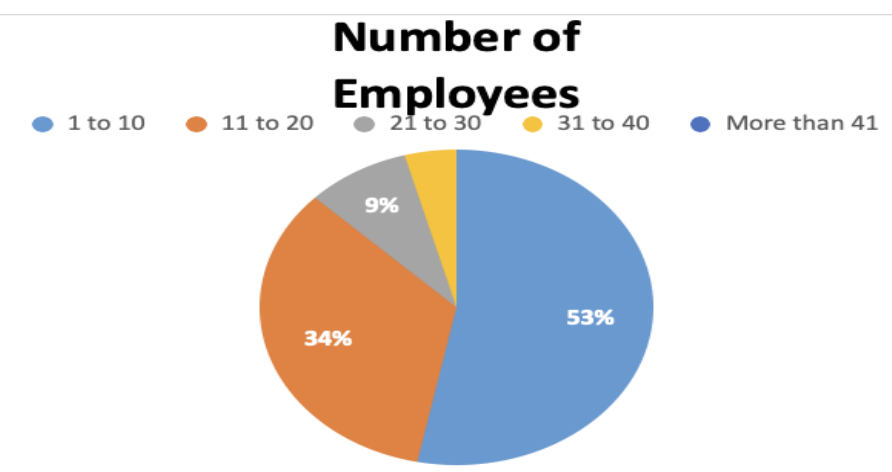

Figure 8. Distribution of hair salons according to the number of employees

\section{RESULTS}

A way to evaluate the responses in the questionnaires was integrating the number of affirmative responses. A chart to compare the knowledge and expectations was designed to prove that the higher the ignorance of the software, the higher the motivation to use it. Also, the higher the transmission of benefits of the software, the higher the willingness to buy it.

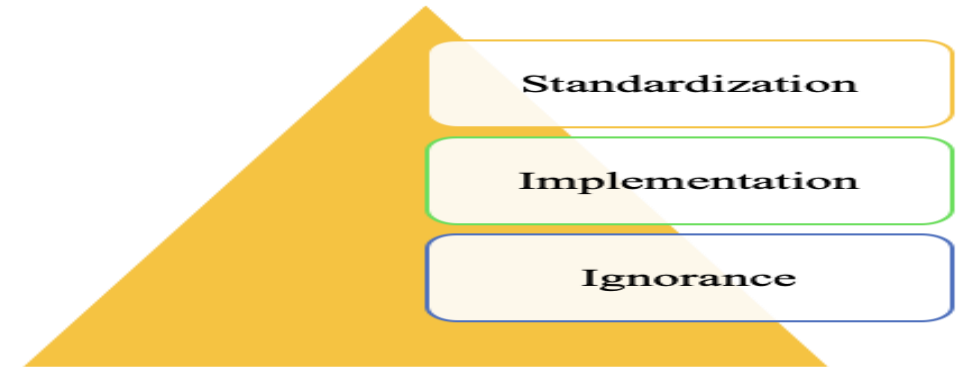

Figure 9. The distribution of appropriation of technology.

This distribution has been determined in order to segregate the participants in a different stage of awareness. It is believed that the lack of knowledge in these users leads to the creation of a gap between the technology and the end user. Therefore, the concept of the invisible tool is coined to provide a reference for SMEs around the world.

The invisible gizmo can be defined as "the digital tool that is not known, used and comprehended by business, industries and the final user, but provides specific solutions, integration and standardization".

The ignorance stage is where the participants answered positively 0 to 9 questions. This means there is a high unawareness of the common procedures in management. The stage of implementation is where the participants answered positively 10 to 18 questions. This means there is a medium unawareness of the common procedures in management. The standardization 
stage is where the participants answered positively 19 to 27 questions. This means there is a low unawareness of the common procedures in management.

The standardization stage shows the users who might be more susceptible to acquiring the new technology to generate integration in their own business. In table 3 we are able to see the distribution of users according to the three stages of evaluation.

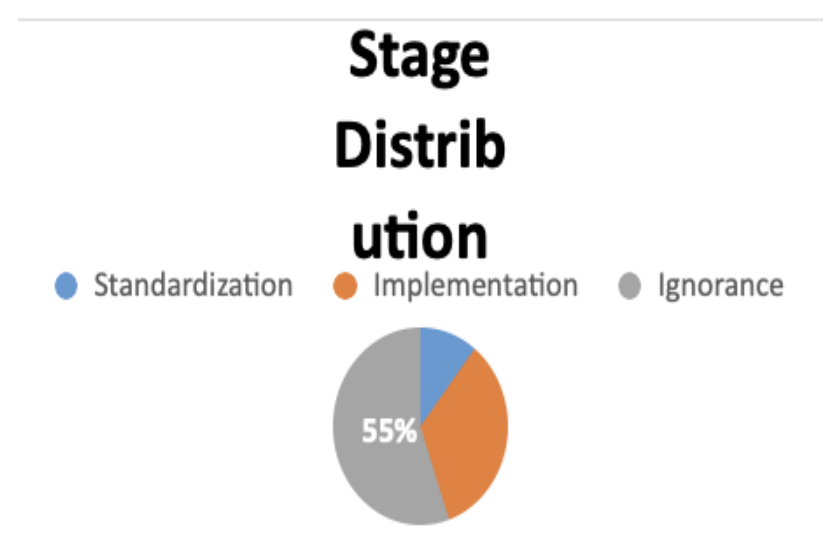

Figure 10. The distribution of appropriation of technology.

\section{DISCUSSION}

This research has successfully identified a relationship between the awareness of technology in SMEs and the potential for standardization. It is important to work in further research as promoted with the ECM once the hair salons acquire the technology and reevaluate their performance and the impact created in these three aspects: sales, customer satisfaction and inventory management. As part of this research, the high level of contribution from SMEs to economies in every country, brings the idea of creating policies which can develop their capacities. Suggestions to each country can be given in the way of taking their SMEs to the standardization of the business processes and bridging the invisible gizmo. Another recommendation is to pay attention in the commerce chambers where training and awareness in relationship to the technology available and the benefits provided.

As a final result, this paper aimed to contribute specifically in the recognition of SMEs as a factor of economic growth and to open a door for entrepreneurs to create competency in the current digitalized world.

\section{AUTHOR CONTRIBUTIONS}

Conceptualization: Wurong Shih, Julián Nevárez Montes

Data Curation: Wurong Shih, Julián Nevárez Montes

Formal Analysis: Wurong Shih, Julián Nevárez Montes

Funding Acquisition: Wurong Shih, Julián Nevárez Montes

Investigation: Wurong Shih, Julián Nevárez Montes

Methodology: Wurong Shih, Julián Nevárez Montes

Project Administration: Wurong Shih, Julián Nevárez Montes

Resources: Wurong Shih, Julián Nevárez Montes

Software: Wurong Shih, Julián Nevárez Montes 
Supervision: Wurong Shih, Julián Nevárez Montes

Validation: Wurong Shih, Julián Nevárez Montes

Visualization: Wurong Shih, Julián Nevárez Montes

Writing - Original Draft: Wurong Shih, Julián Nevárez Montes

Writing - Review \& Editing: Wurong Shih, Julián Nevárez Montes

\section{CONFLICT OF INTEREST STATEMENT}

The authors declare that they have no competing interests.

\section{ACKNOWLEDGEMENT}

All authors contributed equally to the conception and design of the study.

\section{REFERENCES}

Bartlet, C. (2004). Transition management: Text, cases, and readings in cross-border management. Singapore: Irwin McGraw-Hill.

DIXIT, A. K. (2011). A study of issues \& challenges affecting ERP implementation in SMEs. Global Journal of Enterprise Information System, 3(1), 54-62.

Fening, F. A. (2012). Impact of quality management practices on the performance and growth of small and medium sized enterprises (SMEs) in Ghana. International Journal of Business and Social Science, 3(13).

Gattiker, T. F., \& Goodhue, D. L. (2000, January). Understanding the plant level costs and benefits of ERP: will the ugly duckling always turn into a swan?. In Proceedings of the $33 r d$ Annual Hawaii International Conference on System Sciences (pp. 10-pp). IEEE.

Hawking, D. (2004, January). Challenges in Enterprise Search. In ADC (Vol. 4, pp. 15-24).

Hitt, L. M., Wu, D. J., \& Zhou, X. (2002). Investment in enterprise resource planning: Business impact and productivity measures. Journal of management information systems, 19(1), 71-98.

Internet World Stats. (2014, diciembre 18). Internet World Stats. Retrieved from WORLD LANGUAGES $\quad$ BY COUNTRY. $\quad$ Retrieved from http://www.internetworldstats.com/languages.htm

Jasra, J., Hunjra, A. I., Rehman, A. U., Azam, R. I., \& Khan, M. A. (2011). Determinants of business success of small and medium enterprises. International Journal of Business and Social Science, 2(20), 274-280.

Kushnir, K., Mirmulstein, M. L., \& Ramalho, R. (2010). International Finance Corporation. Retrieved from Micro, Small, and Medium Enterprises Around the World: How Many Are There, and What Affects the Count?

Monk, E. F., \& Wagner, B. (2012). Concepts in Enterprise Resource Planning. Boston: Cengage Learning.

Nah, F. F. H., \& Delgado, S. (2006). Critical success factors for enterprise resource planning implementation and upgrade. Journal of Computer Information Systems, 46(5), 99-113.

OECD. (2004). Promoting Entrepreneurship and Innovative SMEs in a Global Economy: 
Towards a More Responsible and Inclusive Globalization. Istanbul: OECD Publications.

Oliver, R. L. (1980). A cognitive model of the antecedents and consequences of satisfaction decisions. Journal of marketing research, 17(4), 460-469.

Ocloo, C. E., Akaba, S., \& Worwui-Brown, D. K. (2014). Globalization and Competitiveness: Challenges of Small and Medium Enterprises (SMEs) in Accra, Ghana. International Journal of Business and Social Science, 5(4), 287-290.

Small and Medium Enterprises Working Group. (2015, September 1). Independent Assessment of the Small \& Medium Enterprises Working Group (SMEWG). Retrieved from www.apec.org

Webb, T. L., Miles, E., \& Sheeran, P. (2012). Dealing with feeling: a meta-analysis of the effectiveness of strategies derived from the process model of emotion regulation. Psychological bulletin, 138(4), 775.

Yoshimura, T., \& Kato, R. (2007). The Policy Environment for Promoting SMEs in Japan. Retrieved from Pacific Economic Cooperation Council. Retrieved from https://www.pecc.org

\section{Copyrights}

Copyright for this article is retained by the author(s), with first publication rights granted to the journal. This is an open-access article distributed under the terms and conditions of the Creative Commons Attribution license (https://creativecommons.org/licenses/by/4.0) 